\title{
Lipocalin 2: a potential therapeutic target for breast cancer metastasis
}

This article was published in the following Dove Press journal:

OncoTargets and Therapy

\section{Chenxia $\mathrm{Hu}^{\prime}$ \\ Ke Yang' \\ Mengjie $\mathrm{Li}^{\prime}$ \\ Weiping Huang ${ }^{2}$ \\ Fengxue Zhang ${ }^{2}$ \\ Hongqi Wang ${ }^{2}$}

'School of Pharmaceutical Science, Guangzhou University of Chinese Medicine, Guangzhou, Guangdong, China; ${ }^{2}$ The Research Center of Basic Integrative Medicine, Guangzhou University of Chinese Medicine, Guangzhou, Guangdong, China
Correspondence: Hongqi Wang

The Research Center of Basic Integrative Medicine, Guangzhou University of Chinese Medicine, No 232, Waihuan Dong Road, Guangzhou University Town, Panyu District, Guangzhou, Guangdong, China

Email hongqiwang@gzucm.edu.cn

\begin{abstract}
Although systematic therapeutic approaches have reduced cancer-associated mortality, metastatic breast cancer can still evade therapy, particularly triple-negative breast cancer, which remains associated with high rates of cancer metastasis and has the worst clinical prognosis. Lipocalin 2 (LCN2) is a secreted glycoprotein that transports small lipophilic ligands. Its abnormal expression serves critical roles in the epithelial-to-mesenchymal transition process, angiogenesis, and cell migration and invasion in breast cancer. Notably, LCN2 functions as an initiator of carcinogenesis and metastasis by involving multiple signaling pathways. The present review aims to summarize research findings on the abnormal expression of LCN2 in breast cancer progression. Furthermore, the review highlights the latest developments of potential LCN2-targeting agents and proposed LCN2-associated molecular mechanisms with regard to breast cancer invasion and metastasis.
\end{abstract}

Keywords: lipocalin 2, breast cancer, metastasis, triple-negative breast cancer, epithelial-tomesenchymal transition, angiogenesis

\section{Introduction}

Lipocalin 2 (LCN2), a member of the lipocalin protein family, is a secreted glycoprotein that transports small lipophilic ligands. Lipocalins are part of a group of $>20$ diverse proteins that exhibit limited amino acid sequence similarity but share a highly conserved 3D structure. This structure consists of a single 8-stranded, antiparallel $\beta$-barrel that forms an enclosing calyx, which is capable of flexible binding and allows lipocalins to transport and present ligands, bind to cell surface receptors and form macromolecular complexes, thereby performing various important functions in cell regulation, proliferation and differentiation. ${ }^{1-3}$

LCN2 is a prominent member of the lipocalin superfamily and was originally identified as a $25-\mathrm{kDa}$ neutrophil glycoprotein based on its covalent binding to matrix metalloproteinase-9 (MMP-9) in human neutrophils. ${ }^{4,5}$ Thus, it is also referred to as neutrophil gelatinase-associated lipocalin (NGAL). When NGAL forms a complex with MMP-9, it can prevent MMP-9 autodegradation and increase the activity of MMP-9 in vitro. ${ }^{6}$ Since MMP-9 can degrade the extracellular matrix and basement membranes, NGAL and the MMP-9/NGAL complex may contribute to tumor progression, invasion and metastasis., ${ }^{7,8}$

Another important LCN2 ligand, first identified by Goetz et al, ${ }^{9}$ is enterochelin, which is released into the extracellular environment by bacteria to capture iron. LCN2 can competitively bind to the secreted enterochelin and deliver enterochelin/ $\mathrm{Fe}^{3+}$ complexes to host cells for degradation, which effectively prevents bacteria from iron acquisition and inhibits bacterial growth. ${ }^{9,10}$ These findings suggest that LCN2 is 
an important innate immunity component against bacterial pathogens and serves a protective role in inflammation, infection, injury and other forms of cellular stress. ${ }^{11-19}$

During the past two decades, abnormal expression of LCN2 has been assigned critical roles in pathological organ conditions, including inflammation, ${ }^{11-13}$ renal damage, ${ }^{15,16}$ liver injury ${ }^{17-19}$ and cancer in several human organs. ${ }^{14,20-27}$ Recently, LCN2 has gained attention as a potential biomarker and a modulator of human cancer. LCN2 protein expression levels have been demonstrated to be increased in various human epithelial cancer types, including breast cancer, ${ }^{20,21}$ ovarian cancer, ${ }^{22}$ thyroid cancer, ${ }^{23}$ lung cancer, ${ }^{24}$ colon cancer $^{25}$ and pancreatic cancer. ${ }^{26}$ Numerous studies have indicated that LCN2 is also associated with high-grade malignancy, relapse proneness, metastasis and poor prognosis in breast cancer. ${ }^{27-36}$

In this review, the most recent reports on abnormal expression of LCN2 in breast cancer cells, orthotopic mouse models of breast cancer and samples from patients with breast cancer were focused on to explore experimental and clinical findings linking LCN2 abnormally expression with breast cancer progression. In addition, this review summarized the latest developments of LCN2-targeted therapy and proposed LCN2-associated mechanisms with regard to breast cancer invasion and metastasis.

\section{LCN2 and prognosis in breast cancer}

Recent studies reported that LCN2 was highly expressed in carcinoma tissues, sera and urine of some patients with breast cancer. Elevated LCN2 expression may be associated with poor prognosis, including estrogen receptor (ER)-negative status, histological grading and lymph node metastasis. The association between LCN2 expression in breast carcinoma and established prognostic markers, as well as the clinical outcome, has been examined in recent years.

Heterogeneous expression of LCN2 was first confirmed at mRNA and protein expression levels in patients with primary breast cancer. Notably, only low expression levels of LCN2 protein have been detected in normal breast ductal epithelium. Furthermore, a significant correlation between LCN2 expression in breast cancer with several other markers of poor prognosis, including ER- or progesterone receptor (PR)-negative status and high S-phase fraction has been identified. ${ }^{28,29}$ Similarly, Gruvberger et $\mathrm{al}^{30}$ and Cheng et $\mathrm{al}^{31}$ indicated that LCN2 is an important gene that is most highly associated with ER-negative breast tumors. ${ }^{30,31}$ Drew et al ${ }^{32}$ revealed that $\mathrm{ER} \alpha$ expression in adipose tissue is inversely associated with adiposity and the expression and release of LCN2, an adipokine, promoting breast cancer cell proliferation and migration. ${ }^{32}$

It has also been reported that LCN2 expression levels were correlated with invasive breast cancer. In cancer tissue and tumor stroma of patients in stages II-III, LCN2 was increased compared with normal epithelium and stroma. Urinary LCN2 expression levels were significantly increased in samples from patients with metastatic breast cancer compared with healthy controls. This suggested that higher expression levels of LCN2 may be predictive of a higher probability of metastatic breast cancer. ${ }^{33}$ Furthermore, a previous study reported 113 women with nonpalpable breast lesions undergoing vacuum-assisted breast biopsy for histological diagnosis and 30 healthy women who served as controls. Notably, the expression levels of MMP-9, NGAL and MMP-9/NGAL complexes were determined in peripheral blood samples. Women with invasive ductal carcinoma exhibited significantly increased levels of MMP-9, NGAL and MMP-9/NGAL compared with healthy women. Significant correlations were observed between MMP-9 and NGAL serum levels with the breast cancer severity score. ${ }^{34}$ Bauer et $\mathrm{al}^{35}$ revealed that there was high correlation of LCN2 expression with human epidermal growth factor receptor 2 (HER-2)/neu overexpression, poor histologic grade, lymph node metastases, a high Ki-67 proliferation index, diseasespecific survival, disease-free survival and ER- and PRnegative status in tumor samples from patients with breast cancer. Furthermore, a similar finding was reported, where high levels of LCN2 were associated with poor overall survival and distant metastasis-free survival in patients with basal-like (mostly ER- and HER2-negative) breast cancer according to analysis of the clinical microarray database of breast cancer, suggesting that serum LCN2 expression levels may serve as a subtype-specific prognostic factor in breast cancer. ${ }^{36}$ In addition, LCN2 may be overexpressed in the immune compartment of breast cancer liver metastases, particularly within smaller lesions. ${ }^{37}$

Overall, high LCN2 expression levels significantly correlated with poor patient prognosis and advanced cancer status. Furthermore, high LCN2 expression is recognized as an independent prognostic biomarker for reduced survival among patients with breast cancer, especially for those suffering from triple-negative breast cancer (TNBC).

\section{LCN2 and TNBC}

TNBC accounts for $12 \%-20 \%$ of all breast cancers and is associated with more aggressive tumor progression and a 
worse prognosis. ${ }^{38,39}$ Metastatic TNBC is a destructive condition that is associated with a high proliferation index, which can lead to visceral and brain metastases. ${ }^{40}$ Furthermore, it is characterized by a lack of ER, PR and HER-2, which results in the resistance to anti-hormone therapies and HER-2-targeting therapies. ${ }^{41,42}$ Average patients' survival of advanced TNBC is $\sim 12$ months, which is much shorter than the duration of survival in other subtypes of breast cancer. Although systematic therapeutic approaches have reduced cancer-specific mortality, TNBC remains associated with high rates of cancer relapse and metastasis. At present, no long-term effective treatment option is available for patients with TNBC. ${ }^{43}$ Therefore, identifying novel biomarkers of TNBC progression and designing specific targets may be of great value for the prevention of metastasis for patients with TNBC.

A recent study identified that $\mathrm{LCN} 2$ is a regulator of angiogenesis, and the downregulation of TNBC-secreted LCN2 is associated with suppressed tumor angiogenesis in breast cancer, making it a potential anti-angiogenic target in TNBC. ${ }^{44}$ Cheng et $\mathrm{al}^{31}$ extended this finding by revealing that LCN2 expression levels in sera were increased in patients with TNBC compared with in those with benign tumors and other subsets of breast cancer. Furthermore, LCN2 was negatively correlated with the ER and PR status. Subsequently, it was observed that silencing of the tumor suppressor gene, hypermethylated in cancer 1 (HIC1), occurred only in TNBC compared with other molecular subtypes of breast cancer. Notably, restoring HIC1 expression in TNBC cells reduced cell invasion, migration and metastasis. Further research identified LCN2 as a critical downstream target of HIC1 in TNBC cells. In addition, autocrine secretion of LCN2 induced by silenced $\mathrm{HIC1}$ activated the protein kinase $\mathrm{B}$ (AKT) signaling pathway through the NGAL receptor, which is associated with TNBC progression. Thus, the HIC1-LCN2 axis may serve as a subtype-specific prognostic biomarker, providing a promising candidate target for TNBC. ${ }^{31}$

\section{Mechanisms of LCN2 in the induction of metastasis in breast cancer}

Metastasis is a complex and multistep process involving various factors, including cancer cells, the tumor microenvironment and interactions with the host immune system. ${ }^{45,46}$ Metastatic cancer persists as a barrier to effective therapy and causes $80 \%$ of cancer-associated fatalities, and so is considered a great challenge in cancer therapy. ${ }^{47}$ For patients with breast cancer, $25 \%-50 \%$ of the patients eventually develop metastasis, which leads to poor prognosis. ${ }^{48,49}$ This review summarized the possible mechanisms of LCN2-mediated breast cancer metastasis. Multiple LCN2-associated signaling pathways and LCN2-regulated genes were suggested (Figure 1).

Epithelial-to-mesenchymal transition (EMT) is a key developmental process that is typically activated during cancer invasion and metastasis. ${ }^{50,51}$ In the EMT process, epithelial cells depolarize, lose cell-to-cell adhesion and transition to cells with elongated, fibroblast-like morphology. Notably, this is a potential mechanism by which tumor cells gain metastatic features. ${ }^{52,53}$ Disseminated cancer cells seem to require self-renewal capability, which is similar to that exhibited by stem cells causing macroscopic metastases. ${ }^{54}$ LCN2 has been indicated to be overexpressed in human breast cancer cells and can upregulate mesenchymal markers, including vimentin and fibronectin, and downregulate the epithelial marker E-cadherin, which induces EMT and significantly increases cell motility and invasion. By contrast, LCN2 silencing in aggressive breast cancer cells can inhibit cell migration and the mesenchymal phenotype. Furthermore, reduced expression levels of $\mathrm{ER} \alpha$ and increased expression levels of the EMT transcription factor Slug were observed with elevated LCN2 expression. However, overexpression of $\mathrm{ER} \alpha$ in LCN2-expressing cells reversed EMT and reduced Slug expression levels, suggesting that ER $\alpha$ negatively regulates LCN2-induced EMT. Furthermore, orthotopic studies have demonstrated that LCN2-expressing breast tumors exhibited a poorly differentiated phenotype and increased local tumor invasion and lymph node metastasis. Taken together, the findings suggested that LCN2 promoted metastasis by inducing EMT through the ER $\alpha /$ Slug axis and that it may be a useful biomarker of breast cancer progression. ${ }^{33,55}$

The influence of LCN2 on the metastatic cascade in the tumor microenvironment has been explored. Ören et $\mathrm{al}^{56}$ revealed the role of stroma-derived LCN2, particularly macrophage-released LCN2, in breast cancer progression. The secretion of LCN2 from macrophages induced EMT in MCF-7 cells and promoted local invasion and migration into the extracellular matrix, which was indicated using a 3D spheroid model. Knockdown and neutralizing antibody studies illustrated that LCN2 can lead to early metastasis in vitro. Furthermore, LCN2 deficiency inhibited breast cancer metastasis in the MMTV-PyMT breast cancer model and a xenograft model inoculating MCF-7 cells. Therefore, stroma-secreted LCN2 contributes to breast cancer progression in vitro and in vivo. ${ }^{56,57}$

In addition, $\mathrm{Li}$ et $\mathrm{al}^{58}$ demonstrated that receptor tyrosineprotein kinase erbB-2 isoform b (ErbB2) (HER2, neu), LCN2 and anemia have all been associated with increased 


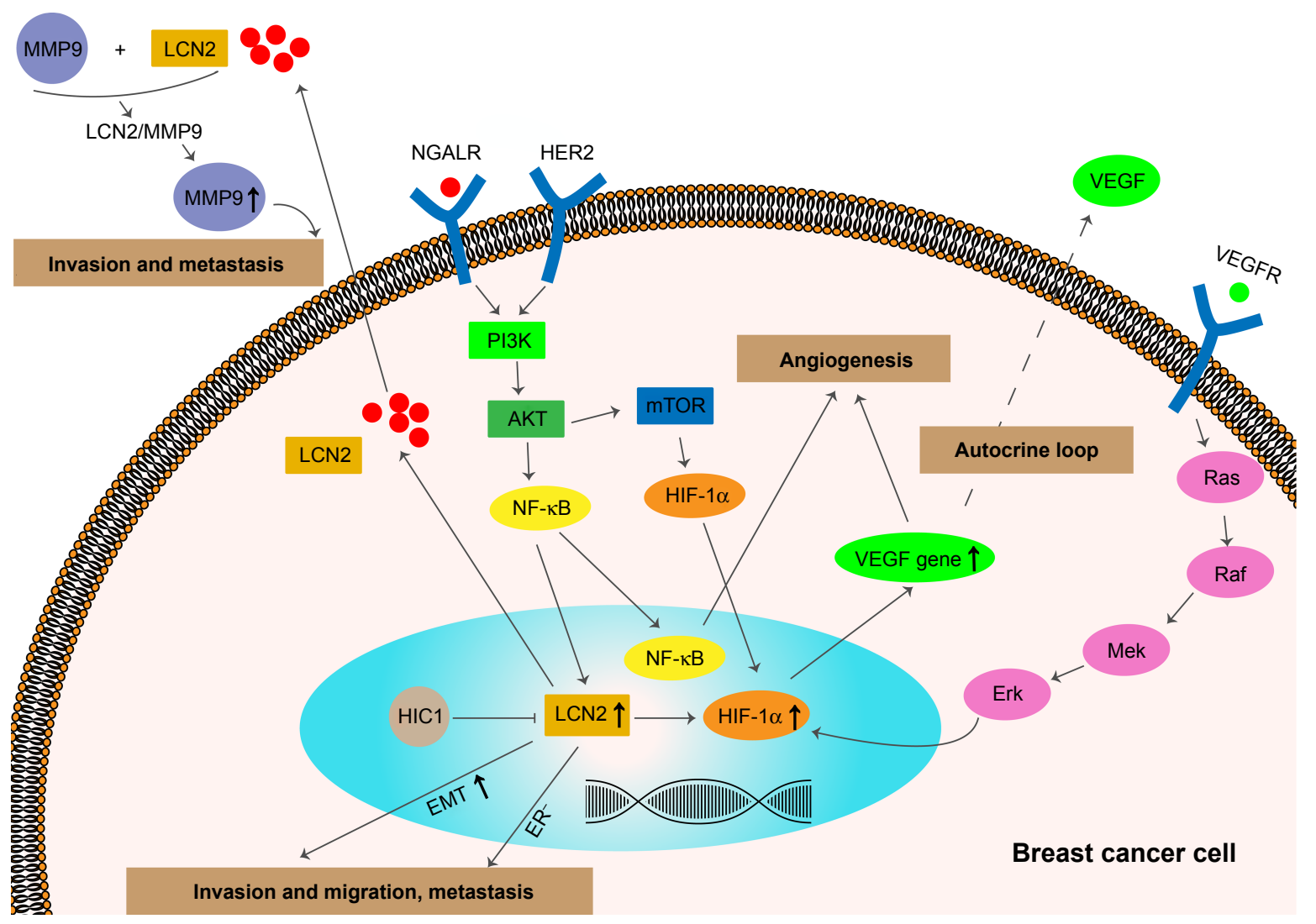

Figure I Possible LCN2-associated mechanisms affecting breast cancer metastasis.

Abbreviations: AKT, protein kinase B; EMT, epithelial-to-mesenchymal transition; ER', estrogen receptor-negative; Erk, extracellular signal-regulated kinase; HER2, human epidermal growth factor receptor 2; HICl, hypermethylated in cancer I; HIF-I $\alpha$, hypoxia inducible factor-I $\alpha$; LCN2, lipocalin 2; MMP-9, matrix metalloproteinase-9; mTOR, mammalian target of rapamycin; NF- KB, nuclear factor- $\mathrm{KB}$; NGALR, neutrophil gelatinase-associated lipocalin receptor; PI3K, phosphoinositide-3-kinase; VEGF, vascular endothelial growth factor; VEGFR, vascular endothelial growth factor receptor.

metastasis and poor prognosis in patients with breast cancer. Their study revealed that ErbB2 overexpression lead to LCN2 upregulation, which is dependent on nuclear factor (NF)- $\mathrm{kB}$ activity and is involved in breast cancer-associated anemia. Therefore, ErbB2, NF- $\mathrm{KB}$ and LCN2 signaling pathways may serve as potential therapeutic targets for breast cancerassociated anemia. ${ }^{58}$ Leng et $\mathrm{l}^{59}$ also explored the molecular mechanisms of delayed breast tumor formation and metastasis, which was accompanied with reduced MMP-9 activity in the blood of MMTV-ErbB2 mice lacking LCN2. Their results suggested that LCN2 expression is upregulated by a HER2/phosphoinositide-3-kinase (PI3K)/AKT/NF- $\mathrm{BB}$ signaling pathway. Decreasing LCN2 significantly reduced the invasion and migration ability of HER2-positive breast cancer cells and murine breast tumor formation and lung metastasis. ${ }^{59}$ However, Berger et $\mathrm{al}^{60}$ proposed that LCN2 is only a potent inducer of primary mammary tumor growth but not a significant promoter of lung metastasis using an in vivo mouse model approach. Therefore, the function and activity regulation mechanism of the LCN2 gene in breast cancer metastasis requires further study.

\section{LCN2 and angiogenesis in breast cancer}

The occurrence and development of solid malignant tumors require a continuous oxygen supply and nutrient absorption. Notably, angiogenesis is necessary for solid tumor growth and progression. As the most important pathway of tumor metastasis, angiogenesis is a crucial component of tumor progression for all subsets of breast cancer. Since tumor neovascularization is characterized by incomplete new tube-like structures, weak vascular walls and increased permeability relative to normal vessels, cancer cells penetrate more easily from the blood vessels into peripheral blood and migrate to distant organs. ${ }^{61}$ Inhibiting angiogenesis is therefore an important therapeutic strategy against human cancer.

It has been reported that LCN 2 can induce the production of hypoxia inducible factor- $1 \alpha$ (HIF- $1 \alpha$ ) and the downstream gene, vascular endothelial growth factor (VEGF), to stimulate angiogenesis in breast cancer cells. Notably, VEGF expression was significantly increased with high LCN2 expression in MCF-7 and MDA-MB-436 cells. VEGF-neutralizing 
antibody studies have demonstrated that VEGF may be essential for LCN2 to exert angiogenic activity. Furthermore, LCN2 can regulate the level of HIF-1 $\alpha$ expression via the extracellular signal-regulated kinase (Erk) signaling pathway to induce VEGF in aggressive MDA-MB-231 cells. LCN2 has also been revealed to significantly enhance VEGF-induced angiogenesis in a mouse model of the corneal pocket assay for angiogenesis study. ${ }^{62}$ In addition, the association of LCN2 promoter methylation with microvessel formation was analyzed. It was indicated that LCN2 promoter unmethylation status (67.2\%) was increased compared with methylation status $(32.8 \%)$ in patients with breast cancer, and LCN2 promoter unmethylation status was associated with aggressive tumor cell phenotype and elevated mean microvessel density. ${ }^{63}$

MMP-9 can cleave a broad range of substrates, including structural components of the extracellular matrix, growth-factor-binding proteins, growth-factor precursors, cell-adhesion molecules and other proteases leading to cancer progression by promoting tumor cell growth, migration, invasion, metastasis and angiogenesis. ${ }^{64}$ Overexpression of LCN2 in MCF-7 human breast cancer cells protects the extracellular matrix remodeling enzyme from autodegradation, resulting in increased MMP-9 expression levels and angiogenesis. ${ }^{65}$ The MMP-9/NGAL complex was detected in the majority of the urine samples from patients with breast cancer but not in those from healthy individuals. The association of LCN2 with MMP-9 is thought to prevent MMP-9 autodegradation and elevate the enzymatic activity of MMP-9 in vitro and in patients with breast cancer. ${ }^{66}$ These results indicate that LCN2 serves an important role in changing the tumor microenvironment and promoting hematogenous metastasis of breast cancer and is expected to be a therapeutic target for the prevention and treatment of breast cancer metastasis.

\section{LCN2 as a potential target for breast cancer metastasis}

Based on the aforementioned findings, the results demonstrate that LCN2 promotes local tumor invasion and cancer metastasis by inducing EMT and stimulating angiogenesis in vitro and in vivo, which suggests that LCN2 may be a promising therapeutic target in inhibiting breast cancer progression. Agents that can diminish and prevent LCN2 secretion tend to have a broad application and be beneficial to patients with breast cancer (Table 1).

Leng et $\mathrm{al}^{59}$ identified that when mice were injected with anti-mouse LCN2 antibody murine breast tumors could form; however, lung metastasis was blocked, which possibly resulted in part by destabilizing the LCN2/MMP-9 complex. The results suggested that inhibition of LCN2 function by an inhibitory monoclonal antibody has potential in breast cancer therapy, particularly by interfering with metastasis in aggressive types of breast cancer. ${ }^{59}$ Following this, it was reported that nuclear factor of activated T-cells 3 (NFAT3) was required to cooperate with estrogen receptor $\alpha$-positive $\left(\mathrm{ERA}^{+}\right.$) and suppress LCN2 gene expression to inhibit

Table I Agents targeting LCN2 and possible LCN2-associated pathways affecting breast cancer metastasis

\begin{tabular}{|c|c|c|c|}
\hline Agents & $\begin{array}{l}\text { Breast cancer lines or } \\
\text { mouse models }\end{array}$ & Mechanisms & References \\
\hline Anti-mLCN2 antibody & $\begin{array}{l}\text { Nude mice implanted with } \\
4 \mathrm{TI} \text { cells }\end{array}$ & Destabilizes LCN2/MMP-9 complex & Leng et al $2009^{59}$ \\
\hline NFAT3 & $\begin{array}{l}\text { ERA }^{+} \text {breast cancer: MCF-7, T-47D, } \\
\text { ZR-75-I and BT- } 474\end{array}$ & NFAT3/LCN2 axis controls motility & Fougère et al $2010^{67}$ \\
\hline C/EBPS & TNBC: MDA-MB-23I & $\begin{array}{l}\text { Represses LCN2 gene promoter activity } \\
\text { and MMPs }\end{array}$ & Wang et al $2011^{68}$ \\
\hline Trastuzumab & HER2-positive SKBr3 & Inhibits LCN2 via the PI3K/AKT pathway & Kumandan et al $2013^{69}$ \\
\hline $\mathrm{HICl}$ & $\begin{array}{l}\text { TNBC: MDA-MB-23I } \\
\text { and MDA-MB-468 }\end{array}$ & $\begin{array}{l}\text { Inhibits LCN2 secretion by the AKT pathway, } \\
\text { reducing cell migration and invasion }\end{array}$ & Cheng et al $2014^{3 !}$ \\
\hline CXCR4 with LCN2 siRNA & $\begin{array}{l}\text { TNBC: MDA-MB-436 } \\
\text { and MDA-MB-23I }\end{array}$ & $\begin{array}{l}\text { Inhibits CXCR } 4 \text { and LCN2 pathways } \\
\text { simultaneously }\end{array}$ & Guo et al $2014^{70}$ \\
\hline ICAM-Len2-LP & TNBC: MDA-MB-23I & $\begin{array}{l}\text { LCN2 knockdown reduces VEGF and } \\
\text { angiogenesis }\end{array}$ & Guo et al $2016^{44}$ \\
\hline MART-IO & $\begin{array}{l}\text { TNBC: MDA-MB-23I } \\
\text { MDA-MB-453 }\end{array}$ & $\begin{array}{l}\text { Suppresses LCN2, decreasing MMP-9 } \\
\text { activity and cell migration and invasion }\end{array}$ & Chiang et al $2016^{71}$ \\
\hline
\end{tabular}

Abbreviations: AKT, protein kinase B; C/EBP, , CCAAT enhancer-binding protein; CXCR4, C-X-C chemokine receptor type 4; ERA ${ }^{+}$, estrogen receptor $\alpha$-positive; HICI, hypermethylated in cancer I; ICAM-Lcn2-LP, intercellular adhesion molecule-I-targeted, Lcn2 siRNA-encapsulating liposome; LCN2, lipocalin 2; MART-I0, I9-nor-2 $\alpha$-(3hydroxypropyl)-I $\alpha, 25(\mathrm{OH})_{2} \mathrm{D}_{3}$; MMP-9, matrix metalloproteinase-9; NFAT3, nuclear factor of activated T-cells 3; PI3K, phosphotylinosital-3-kinase; TNBC, triple-negative breast cancer; VEGF, vascular endothelial growth factor. 
the invasion and migration of $\mathrm{ERA}^{+}$breast cancer cells, including MCF-7, T-47D, ZR-75-1 and BT-474 cells. This finding suggested that an earlier unknown NFAT3/LCN2 axis may critically control motility in breast cancer. ${ }^{67}$ In addition, overexpression of the transcriptional factor CCAAT enhancer-binding protein (C/EBP) induced a strong decrease in LCN2 and MMPs in breast cancer. Furthermore, it directly repressed human LCN2 gene promoter activity by inhibiting its transcription in MDA-MB-231 cells, as determined by the dual-luciferase reporter assay. ${ }^{68}$

Kumandan et $\mathrm{al}^{69}$ reported that trastuzumab significantly inhibited the basal expression of LCN2 in HER2positive SKBr3 human breast cancer cells. However, the unfolded protein response (UPR) could completely attenuate trastuzumab-mediated LCN2 downregulation. Inhibition of the PI3K/AKT signaling pathway in trastuzumab-treated/ UPR-induced SKBr3 cells could partially reduce the upregulation of LCN2 ${ }^{69}$. This also suggested that the PI3K/ AKT signaling pathway is one of the mechanisms inducing LCN2 expression. The synergistic approach of coupling $\mathrm{C}-\mathrm{X}-\mathrm{C}$ chemokine receptor type 4 (CXCR4) axis blockade with LCN2 siRNA inhibited migration in MDA-MB-436 and MDA-MB-231 TNBC cells. The results suggested that drug delivery vehicles engineered to target CXCR4- and LCN2-mediated migratory pathways may effectively slow progression of metastatic breast cancer. ${ }^{70}$ Furthermore, Guo et $\mathrm{al}^{44}$ engineered an intercellular adhesion molecule (ICAM)-1-targeted, LCN2 siRNA-encapsulating liposome (ICAM-Lcn2-LP) delivery system to treat MDA-MB-231 and MCF-10A cells. Their results indicated that ICAMLcn2-LP could bind with human TNBC MDA-MB-231 cells significantly stronger than nonneoplastic MCF-10A cells. In addition, LCN2 knockdown by ICAM-Lcn2-LPs led to a significant reduction in the production of VEGF, which resulted in anti-angiogenesis effects in MDA-MB231 cells in vitro and in vivo. ${ }^{44}$ Other findings have reported that LCN2 was suppressed by $1 \alpha, 25(\mathrm{OH})_{2} \mathrm{D}_{3}$ (vitamin $\mathrm{D}_{3}$ ) and its analog 19-nor-2 $\alpha$-(3-hydroxypropyl)-1 $\alpha, 25(\mathrm{OH})_{2} \mathrm{D}_{3}$ (MART-10), which decreased the abilities of migration and invasion in TNBC cells. Notably, MMP-9 activity was also downregulated by MART-10. ${ }^{71}$

\section{Conclusion}

This review provides strong evidence for the role of LCN2 in aggressive subtypes of breast cancer, metastasis and poor prognosis. Due to its property as a secretory protein, LCN2 can be easily detected in the blood circulation or urine, and previous findings have suggested that LCN2 may be a noninvasive diagnostic and prognostic biomarker for breast cancer progression. It has been identified that LCN2 can actively promote breast cancer metastasis by inducing VEGF production, angiogenesis, EMT and cell migration and invasion through multiple signal pathways, including PI3K/ $\mathrm{AKT} / \mathrm{NF}-\kappa \mathrm{B}$ and HIF-1 $\alpha /$ Erk. Notably, silencing LCN2 in breast cancer cells can reduce tumor progression. Therefore, development of therapeutic agents targeting LCN2 may have vital clinical implications for the treatment of breast cancer metastasis. Given the significant correlation between LCN2 secretion and TNBC cells, accompanied with the rapid metastasis of tumors and limited available treatment methods that result in high mortality rates for TNBC relative to other HER2- and ER-positive breast cancer types, it is of great importance to identify a potential LCN2-targeted therapeutic approach for the prevention and treatment of TNBC.

\section{Acknowledgments}

The present study was supported by the Natural Science Foundation of China (grant no. 81503301), Guangdong Medical Science Foundation (grant no. A2016511) and the Science and Technology Planning Project of Guangdong Province, China (grant no. 2016A050503039).

\section{Disclosure}

The authors report no conflicts of interest in this work.

\section{References}

1. Flower DR, North AC, Sansom CE. The lipocalin protein family: structural and sequence overview. Biochim Biophys Acta. 2000;1482(1-2): 9-24.

2. Bratt T. Lipocalins and cancer. Biochim Biophys Acta. 2000;1482(1-2): 318-326.

3. Åkerstrom B, Flower DR, Salier JP. Lipocalins: unity in diversity. Biochim Biophys Acta. 2000;1482(1-2):1-8.

4. Triebel S, Bläser J, Reinke H, Tschesche H. A 25 kDa alpha 2-microglobulin-related protein is a component of the $125 \mathrm{kDa}$ form of human gelatinase. FEBS Lett. 1992;314(3):386-388.

5. Kjeldsen L, Johnsen AH, Sengeløv H, Borregaard N. Isolation and primary structure of NGAL, a novel protein associated with human neutrophil gelatinase. J Biol Chem. 1993;268(14):10425-10432.

6. Yan L, Borregaard N, Kjeldsen L, Moses MA. The high molecular weight urinary matrix metalloproteinase (MMP) activity is a complex of gelatinase B/MMP-9 and neutrophil gelatinase-associated lipocalin (NGAL). Modulation of MMP-9 activity by NGAL. J Biol Chem. 2001; 276(40):37258-37265.

7. Somiari SB, Shriver CD, Heckman C, et al. Plasma concentration and activity of matrix metalloproteinase 2 and 9 in patients with breast disease, breast cancer and at risk of developing breast cancer. Cancer Lett. 2006;233(1):98-107.

8. Turpeenniemi-Hujanen T. Gelatinases (MMP-2 and -9) and their natural inhibitors as prognostic indicators in solid cancers. Biochimie. 2005; 87(3-4):287-297.

9. Goetz DH, Holmes MA, Borregaard N, Bluhm ME, Raymond KN, Strong RK. The neutrophil lipocalin NGAL is a bacteriostatic agent that interferes with siderophore-mediated iron acquisition. Mol Cell. 2002;10(5):1033-1043. 
10. Berger T, Togawa A, Duncan GS, et al. Lipocalin 2-deficient mice exhibit increased sensitivity to Escherichia coli infection but not to ischemia-reperfusion injury. Proc Natl Acad Sci U S A. 2006;103(6): 1834-1839.

11. Moschen AR, Adolph TE, Gerner RR, Wieser V, Tilg H. Lipocalin-2: a master mediator of intestinal and metabolic inflammation. Trends Endocrinol Metab. 2017;28(5):388-397.

12. Sunil VR, Patel KJ, Nilsen-Hamilton M, Heck DE, Laskin JD, Laskin DL. Acute endotoxemia is associated with upregulation of lipocalin 24p3/ Len2 in lung and liver. Exp Mol Pathol. 2007;83(2):177-187.

13. Singer E, Markó L, Paragas N, et al. Neutrophil gelatinase-associated lipocalin: pathophysiology and clinical applications. Acta Physiol. 2013; 207(4):663-672.

14. Jung M, Mertens C, Bauer R, Rehwald C, Brüne B. Lipocalin-2 and iron trafficking in the tumor microenvironment. Pharmacol Res. 2017;120 146-156.

15. Schmidt-Ott KM. Neutrophil gelatinase-associated lipocalin as a biomarker of acute kidney injury - where do we stand today? Nephrol Dial Transplant. 2011;26(3):762-764.

16. Viau A, El Karoui K, Laouari D, et al. Lipocalin 2 is essential for chronic kidney disease progression in mice and humans. J Clin Invest. 2010;120(11):4065-4076.

17. Borkham-Kamphorst E, van de Leur E, Zimmermann HW, et al. Protective effects of lipocalin-2 (LCN2) in acute liver injury suggest a novel function in liver homeostasis. Biochim Biophys Acta. 2013;1832(5): 660-673.

18. Borkham-Kamphorst E, Drews F, Weiskirchen R. Induction of lipocalin-2 expression in acute and chronic experimental liver injury moderated by pro-inflammatory cytokines interleukin-1 $\beta$ through nuclear factor- $\kappa \mathrm{B}$ activation. Liver Int. 2011;31(5):656-665.

19. Anastasia A, Sabine W, Ralf W. Lipocalin 2 (LCN2) expression in hepatic malfunction and therapy. Front Physiol. 2016;7(9):1-18.

20. Yang J, Moses MA. Lipocalin 2: a multifaceted modulator of human cancer. Cell Cycle. 2009;8(15):2347-2352.

21. Shi H, Gu Y, Yang J, Xu L, Mi W, Yu W. Lipocalin 2 promotes lung metastasis of murine breast cancer cells. J Exp Clin Cancer Res. 2008; 27:83.

22. Cho H, Kim JH. Lipocalin2 expressions correlate significantly with tumor differentiation in epithelial ovarian cancer. J Histochem Cytochem. 2009;57(5):513-521.

23. Iannetti A, Pacifico F, Acquaviva R, et al. The neutrophil gelatinaseassociated lipocalin (NGAL), a NF-kappaB-regulated gene, is a survival factor for thyroid neoplastic cells. Proc Natl Acad Sci U S A. 2008; 105(37):14058-14063.

24. Tong Z, Wu X, Ovcharenko D, Zhu J, Chen CS, Kehrer JP. Neutrophil gelatinase-associated lipocalin as a survival factor. Biochem J. 2005; 391(Pt 2):441-448.

25. Birkenkamp-Demtroder K, Christensen LL, Olesen SH, et al. Gene expression in colorectal cancer. Cancer Res. 2002;62(15):4352-4363.

26. Tong Z, Kunnumakkara AB, Wang H, et al. Neutrophil gelatinaseassociated lipocalin: a novel suppressor of invasion and angiogenesis in pancreatic cancer. Cancer Res. 2008;68(15):6100-6108.

27. Leng X, Wu Y, Arlinghaus RB. Relationships of lipocalin 2 with breast tumorigenesis and metastasis. J Cell Physiol. 2011;226(2):309-314.

28. Stoesz SP, Friedl A, Haag JD, Lindstrom MJ, Clark GM, Gould MN Heterogeneous expression of the lipocalin NGAL in primary breast cancers. Int J Cancer. 1998;79(6):565-572.

29. Wenners AS, Mehta K, Loibl S, et al. Neutrophil gelatinase-associated lipocalin (NGAL) predicts response to neoadjuvant chemotherapy and clinical outcome in primary human breast cancer. PLoS One. 2012;7(10):e45826.

30. Gruvberger S, Ringnér M, Chen Y, et al. Estrogen receptor status in breast cancer is associated with remarkably distinct gene expression patterns. Cancer Res. 2001;61(16):5979-5984.

31. Cheng G, Sun X, Wang J, et al. HIC1 silencing in triple-negative breast cancer drives progression through misregulation of LCN2. Cancer Res. 2014;74(3):862-872.
32. Drew BG, Hamidi H, Zhou Z, et al. Estrogen receptor (ER) $\alpha$-regulated lipocalin 2 expression in adipose tissue links obesity with breast cancer progression. J Biol Chem. 2015;290(9):5566-5581.

33. Yang J, Bielenberg DR, Rodig SJ, et al. Lipocalin 2 promotes breast cancer progression. Proc Natl Acad Sci U S A. 2009;106(10):3913-3918.

34. Provatopoulou X, Gounaris A, Kalogera E, et al. Circulating levels of matrix metalloproteinase-9 (MMP-9), neutrophil gelatinase-associated lipocalin (NGAL) and their complex MMP-9/NGAL in breast cancer disease. BMC Cancer. 2009;9:390.

35. Bauer M, Eickhoff JC, Gould MN, Mundhenke C, Maass N, Friedl A. Neutrophil gelatinase-associated lipocalin (NGAL) is a predictor of poor prognosis in human primary breast cancer. Breast Cancer Res Treat. 2008;108(3):389-397.

36. Györffy B, Lanczky A, Eklund AC, et al. An online survival analysis tool to rapidly assess the effect of 22,277 genes on breast cancer prognosis using microarray data of 1,809 patients. Breast Cancer Res Treat. 2010;123(3):725-731.

37. Christine T. Defining Microenvironment-Induced Transcription Profiles in Breast Cancer Liver Metastases [M]. Montreal: McGill University; 2014.

38. Anders CK, Carey LA. Biology, metastatic patterns, and treatment of patients with triple-negative breast cancer. Clin Breast Cancer. 2009;9(Supp1 2):S73-S81.

39. Bauer KR, Brown M, Cress RD, Parise CA, Caggiano V. Descriptive analysis of estrogen receptor (ER)-negative, progesterone receptor (PR)-negative, and HER2-negative invasive breast cancer, the so-called triple-negative phenotype: a population-based study from the California cancer Registry. Cancer. 2007;109(9):1721-1728.

40. Otvos L, Surmacz E. Targeting the leptin receptor: a potential new mode of treatment for breast cancer. Expert Rev Anticancer Ther. 2011;11(8):1147-1150.

41. Brenton JD, Carey LA, Ahmed AA, Caldas C. Molecular classification and molecular forecasting of breast cancer: ready for clinical application? J Clin Oncol. 2005;23(29):7350-7360.

42. Engebraaten O, Vollan HKM, Børresen-Dale AL. Triple-negative breast cancer and the need for new therapeutic targets. Am J Pathol. 2013; 183(4):1064-1074.

43. Burstein HJ. Patients with triple negative breast cancer: is there an optimal adjuvant treatment? Breast. 2013;22 Suppl 2:S147-S148.

44. Guo P, Yang J, Jia D, Moses MA, Auguste DT. ICAM-1-targeted, Lcn2 siRNA-encapsulating liposomes are potent anti-angiogenic agents for triple negative breast cancer. Theranostics. 2016;6(1):1-13.

45. Quail DF, Joyce JA. Microenvironmental regulation of tumor progression and metastasis. Nat Med. 2013;19(11):1423-1437.

46. Singh BN, Singh HB, Singh A, Naqvi AH, Singh BR. Dietary phytochemicals alter epigenetic events and signaling pathways for inhibition of metastasis cascade: phytoblockers of metastasis cascade. Cancer Metastasis Rev. 2014;33(1):41-85.

47. Talmadge JE, Fidler IJ. AACR centennial series: the biology of cancer metastasis: historical perspective. Cancer Res. 2010;70(14): 5649-5669.

48. Rabbani SA, Mazar AP. Evaluating distant metastases in breast cancer: from biology to outcomes. Cancer Metastasis Rev. 2007;26(3-4): 663-674.

49. Valastyan S, Weinberg RA. Tumor metastasis: molecular insights and evolving paradigms. Cell. 2011;147(2):275-292.

50. Mani SA, Guo W, Liao MJ, et al. The epithelial-mesenchymal transition generates cells with properties of stem cells. Cell. 2008;133(4): 704-715.

51. Thiery JP. Epithelial-mesenchymal transitions in development and pathologies. Curr Opin Cell Biol. 2003;15(6):740-746.

52. Kalluri R, Weinberg RA, Kalluri R, Weinberg RA. The basics of epithelial-mesenchymal transition. J Clin Invest. 2009;119(6): 1420-1428.

53. Scheel C, Weinberg RA. Phenotypic plasticity and epithelialmesenchymal transitions in cancer and normal stem cells? Int J Cancer. 2011;129(10):2310-2314 
54. Kotiyal S, Bhattacharya S. Breast cancer stem cells, EMT and therapeutic targets. Biochem Biophys Res Commun. 2014;453(1):112-116.

55. Ariazi EA, Taylor JC, Black MA, et al. A new role for ER $\alpha$ : silencing via DNA methylation of basal, stem cell, and EMT genes. Mol Cancer Res. 2017;15(2):152-164.

56. Ören B, Urosevic J, Mertens C, et al. Tumour stroma-derived lipocalin-2 promotes breast cancer metastasis. J Pathol. 2016;239(3):274-285.

57. Jung M, Ören B, Mora J, et al. Lipocalin 2 from macrophages stimulated by tumor cell-derived sphingosine 1-phosphate promotes lymphangiogenesis and tumor metastasis. Sci Signal. 2016;9(434):ra64.

58. Li SH, Hawthorne VS, Neal CL, et al. Upregulation of neutrophil gelatinase-associated lipocalin by ErbB2 through nuclear factor-kappaB activation. Cancer Res. 2009;69(24):9163-9168.

59. Leng X, Ding T, Lin H, et al. Inhibition of lipocalin 2 impairs breast tumorigenesis and metastasis. Cancer Res. 2009;69(22):8579-8584.

60. Berger T, Cheung CC, Elia AJ, Mak TW. Disruption of the Lcn2 gene in mice suppresses primary mammary tumor formation but does not decrease lung metastasis. Proc Natl Acad Sci U S A. 2010;107(7):2995-3000.

61. Chan A. Antiangiogenic therapy for metastatic breast cancer: current status and future directions. Drugs. 2009;69(2):167.

62. Yang J, Mcneish B, Butterfield C, Moses MA. Lipocalin 2 is a novel regulator of angiogenesis in human breast cancer. Faseb J. 2013;27(1): $45-50$.

63. Meka P, Jarjapu S, Nanchari SR, et al. LCN2 promoter methylation status as novel predictive marker for microvessel density and aggressive tumor phenotype in breast cancer patients. Asian Pac J Cancer Prev. 2015;16(12):4965-4969.

64. Egeblad M, Werb Z. New functions for the matrix metalloproteinases in cancer progression. Nat Rev Cancer. 2002;2(3):161-174.
65. Fernández CA, Yan L, Louis G, Yang J, Kutok JL, Moses MA. The matrix metalloproteinase-9/neutrophil gelatinase-associated lipocalin complex plays a role in breast tumor growth and is present in the urine of breast cancer patients. Clin Cancer Res. 2005;11(15):5390-5395.

66. Yan L, Borregaard N, Kjeldsen L, Moses MA. The high molecular weight urinary matrix metalloproteinase (MMP) activity is a complex of gelatinase B/MMP-9 and neutrophil gelatinase-associated lipocalin (NGAL). Modulation of MMP-9 activity by NGAL. J Biol Chem. 2001;276(40):37258-37265.

67. Fougère M, Gaudineau B, Barbier J, et al. NFAT3 transcription factor inhibits breast cancer cell motility by targeting the Lipocalin 2 gene. Oncogene. 2010;29(15):2292-2301.

68. Wang L, Li H, Wang J, et al. C/EBP $\zeta$ targets to neutrophil gelatinaseassociated lipocalin (NGAL) as a repressor for metastasis of MDAMB-231 cells. Biochim Biophys Acta. 2011;1813(10):1803-1813.

69. Kumandan S, Mahadevan NR, Chiu K, Delaney A, Zanetti M. Activation of the unfolded protein response bypasses trastuzumab-mediated inhibition of the PI-3K pathway. Cancer Lett. 2013;329(2):236-242.

70. Guo P, You JO, Yang J, Jia D, Moses MA, Auguste DT. Inhibiting metastatic breast cancer cell migration via the synergy of targeted, $\mathrm{pH}-$ triggered siRNA delivery and chemokine axis blockade. Mol Pharm. 2014;11(3):755-765.

71. Chiang K-C, Yeh T-S, Chen S-C, et al. The vitamin D analog, MART-10, attenuates triple negative breast cancer cells metastatic potential. Int $J$ Mol Sci. 2016;17(4):606.
OncoTargets and Therapy

\section{Publish your work in this journal}

OncoTargets and Therapy is an international, peer-reviewed, open access journal focusing on the pathological basis of all cancers, potential targets for therapy and treatment protocols employed to improve the management of cancer patients. The journal also focuses on the impact of management programs and new therapeutic agents and protocols on

\section{Dovepress}

patient perspectives such as quality of life, adherence and satisfaction The manuscript management system is completely online and includes a very quick and fair peer-review system, which is all easy to use. Visit http://www.dovepress.com/testimonials.php to read real quotes from published authors. 